\title{
Utilizing the Concept of the Shadow in Fiction Writing in order to Facilitate a Dialogue between Ego Consciousness and the Unconscious
}

\author{
Madeline Sonik
}

In the creating of fiction, the Jungian concept of the human shadow and the mechanisms of shadow possession and projection can be utilized in facilitating a dialogue between the writer's conscious ego intent and her unconscious. This dialogue can assist in producing more psychically authentic fiction, in broadening a writer's consciousness, and in enhancing the creative process.

In Jung's 1922 lecture, later translated and published as On the Relation of Analytical Psychology to Poetry, he distinguishes between an introverted and extraverted attitude in the creation of literature. "The introverted attitude is characterized by the subject's assertion of his conscious intentions and aims against the demands of the object, whereas the extraverted attitude is characterized by the subject's subordination to the demands which the object makes upon him" (p.73). In the first instance, the artist becomes "so identified with his work that his intentions and his faculties are indistinguishable from the act of creation itself" (p.72). In the second, the artist feels she is overtaken by something greater than herself, and must "follow where it leads" (p.73). In both attitudes, extraverted and introverted, Jung makes clear that "the act of creation itself" has an energy and movement, which is unconscious and separate from, though potentially identifiable with, the artist's ego consciousness.

In this paper, I wish not only to consider the creative relationship of ego intent and unconscious psychic movement in the production of prose fiction, but also to demonstrate how the Jungian conception of the shadow can be used in the production of fiction. As a literary artist, I have become strikingly aware of the fact that my writing does not issue from my ego's consciousness alone, that indeed, conscious intent is only a limited function when not tied to the unconscious energy and direction or what Jung calls "the creation of art itself." As a creative writing educator and former student, my concern is that creative writing continues to be taught with reference to the conscious intention of the writer alone. In high school creative writing classrooms, we see this particularly when the students" "story outlines" become the definitive road maps for their creations. If the unconscious should attempt to inform, and something surprising or unexpected should emerge, 
the door is swiftly shut against it. Rather than learning to allow ego consciousness to engage in a productive dialogue with the unconscious, or alternately learning how to develop ego consciousness in an effort of its becoming a strong vehicle for delivery of the unconscious contents, students learn to suspect anything they cannot immediately own as their predetermined intentions.

Because educators neglect the important role of the unconscious in the production of fiction and stress the student's ego intention, they also neglect assisting students in developing useful tools and strategies for facilitating a good creative relationship between the two.

One of the ways a writer may seek to facilitate the relationship between conscious intent and unconscious content is by having, as a starting point, a conscious intention of unearthing unconscious content-for example, as I will demonstrate in the following, by employing the concept of the Jungian shadow as a tool in story production.

Carl Jung related a dream in his work Memories, Dreams, Reflections in which he found himself in a windstorm carrying a small, flickering light while being pursued from behind by a dark, overwhelming creature. On waking, he wrote: "I realized at once that the figure was my own shadow on the swirling mists, brought into being by the little light I was carrying. I knew too that this little light was my consciousness, the only light I have. Though infinitely small and fragile in comparison with the powers of darkness, it is still a light, my only light" (pp. 8788). He developed the term "shadow" as a metaphor for that part of the unconscious that resides just beyond one's ego consciousness. The shadow is composed of those qualities and traits that an individual has rejected. The collective also has a shadow. In the collective shadow, those things that have been deemed inappropriate in a particular society or culture reside; for example, greed, rage, and hatred inhabit our collective shadow (Zweig, 1990).

In literature, the Jungian concept of the human shadow and the mechanisms of shadow possession and projection can be identified in works such as The Strange Case of Dr. Jekyll and Mr. Hyde in which a quiet, mild-mannered doctor, whose conscious objective is to help humankind, becomes a lascivious, murdering beast. There is a particular authenticity in this fiction, for although Dr. Jekyll and Mr. Hyde, as they exist in Stevenson's text, do not exist and never could have existed in the "real world," the story conveys the psychic dynamic of shadow possession, which is psychically credible, and in so being engages the reader. The same can be said for the novel The Picture of Dorian Grey, which depicts the psychic dynamic of shadow projection. Dorian Grey projects his shadow onto his portrait. It is his own image that carries all the dark and unacceptable qualities of personality that he himself wishes not to acknowledge. At the end of the novel, his desire to destroy the portrait results from a final denial to carry his shadow. 


\section{Sonik}

As a writer of fiction, I have found that by consciously using the concept of the shadow in story production, I am more readily able to engage with unconscious content. In the following pages, I will reflect upon two stories I authored in which the psychological concept and mechanics of the human shadow were consciously employed.

The first work in which I began experimenting with the conception and dynamics of the human shadow is an epistolary story called "Abiding Peace." I began the story by envisioning the archetypal "good daughter." I decided to conjure such a character into being because at the time my mother had recently died; I was struggling with my own inner "good daughter" shadow and attempting to find an authentic place between this shadow and her opposite. Her opposite, in my case, is what Jung might call "the resistant daughter." According to Jung, both the "good daughter" and the "resistant daughter" arise through a mother complex (Jung, 1982). The good daughter is unable to differentiate herself from her mother while the resistant daughter, in order to differentiate herself, rebels against the mother. "The motto of this type is, "Anything, so long as it is not like Mother!" (p.118). Both these archetypal patterns when unconscious (as we can say of all unconscious archetypal patterns) prevent the genuine expression of an individual. Without even thinking, the daughter acts out of compliance or resistance to the mother, and often it is only after the mother is dead that the daughter can begin to question her responses and develop a stance of her own uninfluenced by her mother's taste, values and attitudes.

In "Abiding Peace," I had no preconceived notions of what this "good daughter's" shadow might look like. In this story, I began with an attitude of exploration and allowed the unconscious to supply the information. The name of the character, "Dora," arrived without my really thinking too much about it. Later, when I reflected on the choice of the name, I associatively thought of "dormouse" and considered how the name could be accentuating a diminished status. I also thought of the French verb "dormir," "to sleep," and considered how this perhaps could be telling of the great unconsciousness of this particular character. Rather than taking control and consciously guiding the story in any given direction, these realizations simply affirmed my trust in allowing the unconscious to inform. I allowed Dora to reveal herself to me through the letters she was writing to her dead mother.

The letter is a useful creative writing exercise both for fiction and non-fiction writers and in autobiographical writing, particularly, can contain therapeutic benefits. In fiction writing, the letter one character writes to another not only reveals the conscious position of the character writing but also can work to reveal a subtext or the "shadow story" that is intuitively pieced together by the reader. The 
letter is an extremely good way of unearthing a character's shadow in that the immediate subjectivity of a letter, particularly when it is directed to another specific character, narrows the field of consciousness in a story. From a Jungian perspective, the more limited the field of consciousness, the greater the impact of the shadow.

In technical aspects of writing, we can consider this concept in relation to points of view. A conventional first-person point of view will always be immediately open to the strong influence of the narrator's shadow, since what the character presents to the reader in the narrative is only ever what he/she is consciously aware of. An omniscient third-person narrator, on the other hand, possesses a broad and diffuse field of consciousness that can include that of the many characters. The "shadow story" of the narrator, therefore, is absent, while that of the characters themselves becomes more prominent.

As a writer, pursuing the shadow of the "good daughter" in "Abiding Peace," I attempted to remain constantly alert to the underside of Dora's statements. At one point, she writes the following:

I've realized for the first time in my life how much I depended on your being here for me. When I was trying to make the arrangements, I couldn't decide on the casket. It's crazy, but my first response was to want to ask you - and then I remembered you were dead and I could never ask you anything again. I miss you, Mum, and wish you were still here to tell me what to do. (p. 45)

Besides seeing the surface grief she is expressing at the loss of a maternal advisor, I take note of Dora's paralysis, her seeming inability to act without her mother. What is not directly expressed but shown in shadow is the frustration and rage caused by being paralysed and dependent.

Again, as I wrote this story, I did not allow these thoughts to direct the course of the story, but instead allowed them simply to inform the unconscious, taking a position toward the story as a listener rather than a self-conscious creator. I allowed Dora to write her letters, and I paid attention to what the letters said - both what they directly stated and what was indirectly shown. The concept of a writer "listening" to her story as it unfolds rather than consciously directing the story's unfolding is fundamentally opposed to what is taught in elementary and high school creative writing curricula. Also, in university writing workshops, approaches to the process of writing are rarely discussed, as the product itself becomes focal.

The process of rendering by "listening," and specifically in this instance by listening to the character's conscious and shadow content of a developing work, must be undertaken with an active consciousness; I therefore call this writing process technique "conscious listening." 


\section{Sonik}

"Conscious listening" can be seen to work similarly to the "observer effect" in quantum physics: the idea that "vigilance operating through continual observation actually alters the physical atomic world" (Woolf, 1994, p. 70). In the instance of a work of fiction, continual observation through conscious listening subtly delineates a story's development — and it is the subtlety and the spontaneity this subtlety produces that are of most value in this process technique.

When I began writing “Abiding Peace," I didn't know that Dora had murdered her mother and was surprised when the cumulative evidence she supplied, both in her conscious narrative and its shadow, finally allowed me to figure it out. The feeling, then, was not so much one of consciously directing an outcome as of having witnessed the outcome and its inevitability.

The other story that I worked with using Jung's concept of the shadow is entitled "The Black Wig." The genesis of this fiction also has its roots in a personal life experience. When I was a teenager, I worked as a chambermaid in various hotels. In one particular hotel, there was a dowdy, timid maid with thinning hair who had been cast in the role of scapegoat for all the housekeeping problems by a rather domineering and bullying head housekeeper. The timid maid seemed to me to have lost both her self-esteem and her self-respect. I asked myself where her self-assertion, confidence and life force had gone. She seemed an extremely responsible woman in regards to her work and family, but either through a martyr complex or just a lack of self-esteem she was unable to stand up for herself. Eventually, she was fired from this job and no one knew what became of her. Later, when I learned about Jung's concepts of projection and the shadow and began experimenting with them in writing, Lynne, the dowdy chambermaid, was a character who came to mind as one whose unconscious must harbour many collective and conventionally positive traits, such as assertion, animation and dynamism. Her appearance in the world was that of the archetypal victim, who through no fault of her own, other than perhaps an inability to believe she was worthy of anything better, had become trapped in this great impoverishment.

When I began to ask the questions again, "Where did this woman's life force go?" I thought of her thinning hair and then in my mind's eye saw the numinous black wig, for things in the shadow tend to take on an eerie numinosity which can attract and possess.

Unlike "Abiding Peace," "The Black Wig" is written from a third-person limited omniscient viewpoint, and therefore the shadow of the character is not revealed so much by what she says and does not say as by what the narrator tells us she thinks and does. As I watched, the shadow of the victim began taking shape and taking possession through numinous and collectively loaded objects of a hotel guest: a wig, some hand cream. It seemed inevitable that Lynne must dress herself 
completely in the hotel guest's clothing. It also seemed inevitable that the head housekeeper must catch her at it. What I was most uncertain about and what did not reveal itself to me until the very moment was how she would respond to being confronted. If I had tried to consciously direct the movement of the story at this point, it is unlikely that the element of surprise achieved in the story would have occurred. It was the character Lynne herself, in my imagination, who responded to the confrontation by embracing the identity of the hotel guest. Her response surprised me, yet was completely consistent with the development of her shadow possession, which I had remained conscious of throughout.

Using the concept of the shadow consciously is a method writers and writing educators can use that will provide greater awareness of creative writing processes while producing psychically authentic fiction. Besides acknowledging the existence of a discernable ego consciousness that must surrender to and/or collaborate with the demands of the creative unconscious, such methods also promote an opportunity to strengthen and trust the important creative communication between the two.

\section{Works Cited}

Jung, Carl. Aspects of the Feminine. Trans. R.F.C. Hull. New Jersey: Princeton University Press, 1982.

Jung, Carl. Memories, Dreams, Reflections. Trans. C. Winston \& R. Winston. New York: Vintage Books, 1963.

Jung, Carl. The Spirit in Man, Art, and Literature. Trans. R.F.C. Hull. New Jersey: Princeton University Press, 1966.

Sonik, Madeline. “Abiding Peace.” Ellery Queen's Mystery Magazine 577, 1990.

Stevenson, Robert L. The Strange Case of Dr. Jekyll and Mr. Hyde. London: Hesperus Press, 2003.

Wilde, Oscar. The Picture of Dorian Grey. New York: Modern Library, 1998.

Wolf, Fred A. The Dreaming Universe. New York: Simon \& Schuster, 1994.

Zweig, Connie. Meeting the Shadow: The Hidden Power of the Dark Side of Human Nature. Los Angeles: Jeremy P. Tarcher, Inc., 1991. 